\title{
STATE OF THE CLIMATE IN 2020
}

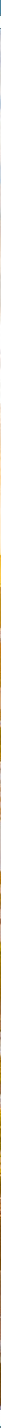

\section{Special Supplement to the}

Bulletin of the American Meteorological Society

Vol. 102, No. 8, August 2021 


\section{Cover credits:}

Cover graphic data from atmospheric $\mathrm{CO}_{2}$ time series at Mauna Loa Dr. Pieter Tans, NOAA/GML (gml.noaa.gov/ccgg/trends/) and Dr. Ralph Keeling, Scripps Institution of Oceanography (scrippsco2.ucsd.edu/). See also Fig. 2.50a of this report.

Background graphic: Empty freeway streets in Los Angeles with almost no vehicles and people due to coronavirus (COVID-19) virus outbreak and stay at home order and mandatory quarantine. Credit: iStock/Getty Images Plus/vlvart.

\section{How to cite this document:}

\section{Citing the complete report:}

Blunden, J. and T. Boyer, Eds., 2020: "State of the Climate in 2020". Bull. Amer. Meteor. Soc., 102 (8), Si-S475, doi:10.1175/2021BAMSStateoftheClimate.1.

Special Supplement to the Bulletin of the American Meteorological Society, Vol. 102, No. 8, August, 2021, https://doi.org/10.1175/2021BAMSStateoftheClimate.1

Corresponding author: Full report: Jessica Blunden / jessica.blunden@noaa.gov 


\section{STATE OF THE CLIMATE IN 2020 TABLE OF CONTENTS}

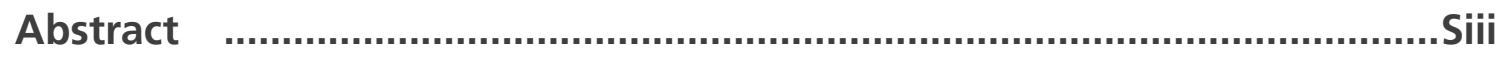

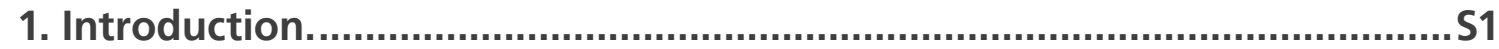

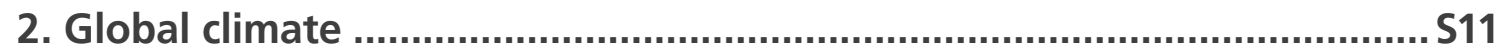

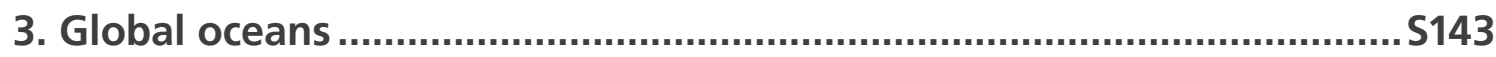

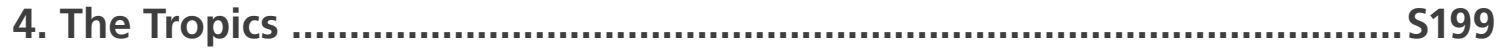

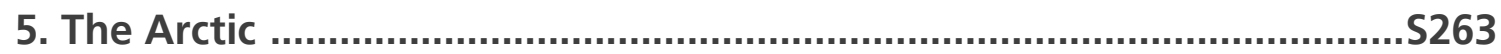

6. Antarctica and the Southern Ocean ..................................................5317

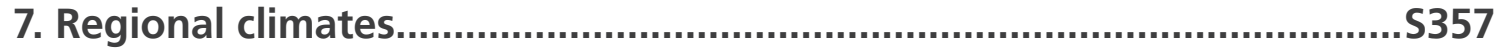

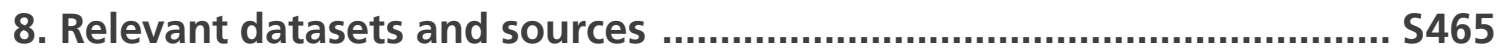


In 2020, the dominant greenhouse gases stored in Earth's atmosphere continued to increase. The annual global average carbon dioxide $\left(\mathrm{CO}_{2}\right)$ concentration at Earth's surface was 412.5 $\pm 0.1 \mathrm{ppm}$, an increase of $2.5 \pm 0.1 \mathrm{ppm}$ over 2019 , and the highest in the modern instrumental record and in ice core records dating back 800,000 years. While anthropogenic $\mathrm{CO}_{2}$ emissions were estimated to decrease around $6 \%-7 \%$ globally during the year due to reduced human activities during the COVID-19 pandemic, the reduction did not materially affect atmospheric $\mathrm{CO}_{2}$ accumulation as it is a relatively small change, less even than interannual variability driven by the terrestrial biosphere. The net global uptake of $\sim 3.0$ petagrams of anthropogenic carbon by oceans in 2020 was the highest in the 39-year record and almost 30\% higher than the 1999-2019 average.

Weak El Niño-like conditions in the eastern equatorial Pacific Ocean in early 2020 cooled and transitioned to a moderate La Niña later in the year. Even so, the annual global surface temperature across land and oceans was among the three highest in records dating to the mid- to late 1800s. In Europe, 17 countries reported record high annual mean temperatures, contributing to the warmest year on record for the European continent. Elsewhere, Japan, Mexico, and Seychelles also experienced record high annual mean temperatures. In the Caribbean, Aruba, Martinique, and St. Lucia reported their all-time monthly maximum temperatures. In the United States, Furnace Creek in Death Valley, California, reached $54.4^{\circ} \mathrm{C}$ on 16 August-the hottest temperature measured on Earth since 1931, pending confirmation. North of $60^{\circ} \mathrm{N}$, the annual mean temperature over Arctic land areas was $2.1^{\circ} \mathrm{C}$ above the $1981-2010$ average, the highest in the 121-year record. On 20 June, a temperature of $38^{\circ} \mathrm{C}$ was observed at Verkhoyansk, Russia $\left(67.6^{\circ} \mathrm{N}\right)$, provisionally the highest temperature ever measured within the Arctic Circle.

Near the opposite pole, an atmospheric river-a long, narrow region in the atmosphere that transports heat and moisture from sub-tropical and midlatitudes_-brought extreme warmth from sub-tropical and midlatitudes to parts of Antarctica during austral summer. On 6 February, Esperanza Station recorded a temperature of $18.3^{\circ} \mathrm{C}$, the highest temperature recorded on the continent, surpassing the previous record set in 2015 by $1.1^{\circ} \mathrm{C}$. The warmth also led to the largest late-summer surface melt event in the 43 -year record, affecting more than $50 \%$ of the Antarctic Peninsula. In August, daily sea ice extent in the waters surrounding Antarctica shifted from below to above average, marking the end of persistent below-average sea ice extent since austral spring 2016.
In the Arctic, when sea ice reached its annual maximum extent in March, thin, first-year ice comprised $\sim 70 \%$ of the ice; the thickest ice, which is usually more than four years old, had declined by more than $86 \%$ since 1985 to make up just $2 \%$ of total ice in 2020. When the minimum sea ice extent was reached in September, it was the second smallest except for 2012 in the 42-year satellite record. The Northern Sea Route along the Siberian coast was open for about 2.5 months, from late July through mid-October, compared to less than a month typically.

Glaciers across the global cryosphere lost mass for the 33rd consecutive year, and permafrost temperatures continued to reach record highs at many high latitude and mountain locations. In the Northern Hemisphere, lakes froze three days later and thawed 5.5 days earlier on average. In Finland, the average duration of lake ice was 42 days shorter. Record high spring temperatures in central Siberia drove rapid snow melt that contributed to the lowest June snow cover extent across Eurasia in the 54-year record.

As is typical, some areas around the world were notably dry in 2020 and some were notably wet. The Middle East experienced an extreme drought during autumn, with most places reporting no precipitation in October. In South America, the Bolivian lowlands suffered one of its most severe droughts on record during autumn. Drought also spanned the Chaco and Pantanal in Bolivia, Paraguay, and southern Brazil. The Paraguay River shrank to its lowest levels in half a century. A decadal "mega drought" in south-central Chile continued through its 11th year, with extreme conditions in the most populated areas. Argentina reported its driest year since 1995. In North America, drought continued to prevail in the West.

The lack of moisture in drought-stricken regions often provide ideal conditions for fire. Total fire emissions in the western United States in 2020 were almost three times higher than the 2003-10 mean. The Arctic experienced its highest fire year in terms of carbon emitted into the atmosphere, surpassing the record set in 2019 by 34\%, with most of the fires occurring in Arctic Asia. In the tropics, the Amazon saw its highest fire activity since 2012, while fire activity in tropical Asia_-including Indonesia-was one of the lowest on record, related to wet conditions as La Niña evolved during the fire season.

The 2020 Southwest Asian Monsoon season (June-September) was the wettest since 1981, also coincident with the emergence of La Niña. The Meiyu rainy season, which usually occurs between July and August over the Yangtze and Huaihe River Valleys of China, was extended by two months in 2020. The 
May-October total rainfall averaged over the area was the most since the start of the record in 1961. Associated severe flooding affected about 45.5 million people.

A widespread desert locust infestation during 2019-20 impacted equatorial and northern East Africa, as heavy rains and prevailing winds were favorable for breeding and movement of swarms across Kenya, Ethiopia, northeastern Somalia, Uganda, South Sudan, and northern Tanzania. The massive infestation destroyed thousands of square kilometers of cropland and pasture lands, resulting in one million people in need of food aid in Ethiopia alone. Extremely heavy rains in April also triggered widespread flooding and landslides in Ethiopia, Somalia, Rwanda, and Burundi. The Lake Victoria region was the wettest in its 40-year record.

Across the global oceans, the average ocean heat content reached a record high in 2020 and the sea surface temperature was the third highest on record, surpassed only by 2016 and 2019. Approximately $84 \%$ of the ocean surface experienced at least one marine heatwave (MHW) in 2020. For the second time in the past decade, a major MHW developed in the northeast Pacific, covering an area roughly six times the size of Alaska in September. Global mean sea level was record high for the ninth consecutive year, reaching $91.3 \mathrm{~mm}$ above the 1993 average when satellite measurements began, an increase of $3.5 \mathrm{~mm}$ over 2019. Melting of the Greenland Ice Sheet accounted for about $0.8 \mathrm{~mm}$ of the sea level rise, with an overall loss of 293 \pm 66 gigatons of ice.
A total of 102 named tropical storms were observed during the Northern and Southern Hemisphere storm seasons, well above the 1981-2010 average of 85. In the North Atlantic, a record 30 tropical cyclones formed, surpassing the previous record of 28 in 2005. Major Hurricanes Eta and lota made landfall along the eastern coast of Nicaragua in nearly the same location within a two-week period, impacting over seven million people across Central America. In the western North Pacific, Super Typhoon Goni was the strongest tropical cyclone to make landfall in the historical record and led to the evacuation of almost 1 million people in the Philippines. Very Severe Cyclonic Storm Gati was the strongest recorded cyclone to make landfall over Somalia. Bosaso, in northeast Somalia, received $128 \mathrm{~mm}$ of rainfall in a 24-hour period, exceeding the city's average annual total of $100 \mathrm{~mm}$.

Above Earth's surface, the annual lower troposphere temperature equaled 2016 as the highest on record, while stratospheric temperatures continued to decline. In 2020, the stratospheric winter polar vortices in both hemispheres were unusually strong and stable. Between December 2019 and March 2020, the Arctic polar vortex was the strongest since the beginning of the satellite era, contributing to record low stratospheric ozone levels in the region that lasted into spring. The anomalously strong and persistent Antarctic polar vortex was linked to the longest-lived, and 12th-largest, ozone hole over the region, which lasted to the end of December. 


\section{STATE OF THE CLIMATE IN 2020 INTRODUCTION}

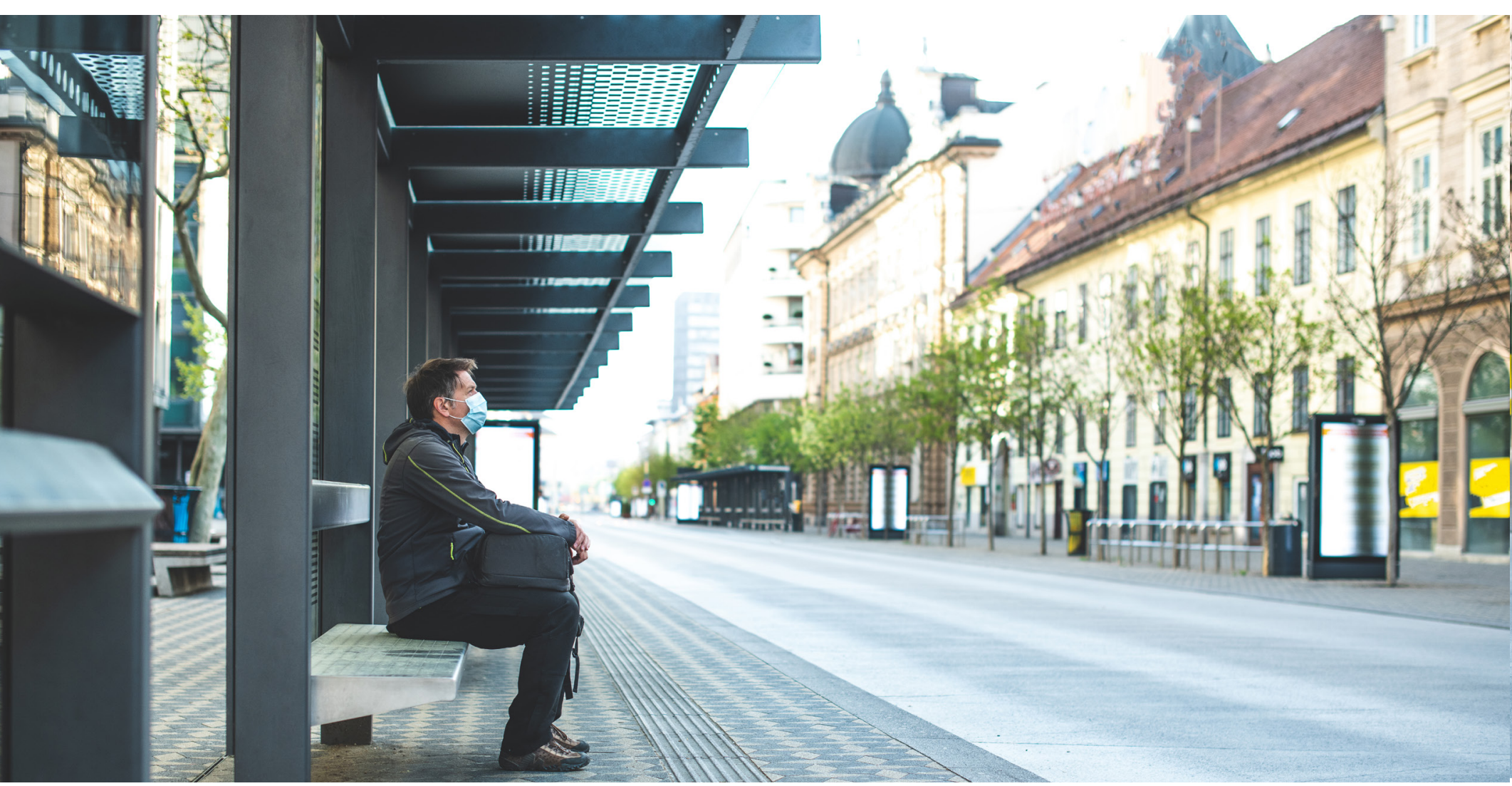

Emissions from fossil fuel use in $\mathbf{2 0 2 0}$ dropped by around $6 \%$ to $7 \%$ over 2019 due to decreased activity during the pandemic (section 2g1); however atmospheric concentration of carbon dioxide $\left(\mathrm{CO}_{2}\right)$, still reached the highest levels in the modern climate record.

Citing this chapter: Boyer, T., J. Blunden, and R. J. H. Dunn. 2021: Introduction [in "State of the Climate in 2020"]. Bull. Amer. Meteor. Soc., 102 (8), S1-S10, https://doi.org/10.1175/2021BAMSStateoftheClimate_Intro.1.

Special Supplement to the Bulletin of the American Meteorological Society Vol.102, No. 8, August, 2021

The Introduction is one chapter from the State of the Climate in 2020 annual report. Compiled by NOAA's National Centers for Environmental Information, State of the Climate in 2020 is based on contributions from scientists from around the world. It provides a detailed update on global climate indicators, notable weather events, and other data collected by environmental monitoring stations and instruments located on land, water, ice, and in space. The full report is available from https://doi.org/10.1175/2021BAMSStateoftheClimate.1.

https://doi.org/10.1175/2021BAMSStateoftheClimate_Intro.1

Corresponding author, Introduction: Jessica Blunden / jessica.blunden@noaa.gov 


\title{
STATE OF THE CLIMATE IN 2020 Introduction
}

\author{
Editors \\ Jessica Blunden \\ Tim Boyer

\section{Chapter Editors} \\ Freya Aldred \\ Peter Bissolli \\ Howard J. Diamond \\ Matthew L. Druckenmiller \\ Robert J. H. Dunn \\ Catherine Ganter \\ Nadine Gobron \\ Gregory C. Johnson \\ Tim Li \\ Rick Lumpkin \\ Ademe Mekonnen \\ John B. Miller \\ Twila A. Moon \\ Ahira Sánchez-Lugo \\ Ted A. Scambos \\ Carl J. Schreck III \\ Sharon Stammerjohn \\ Richard L. Thoman \\ Kate M. Willett \\ Technical Editor \\ Andrea Andersen
}

\section{BAMS Special Editor for Climate}

Michael A. Alexander

\section{American Meteorological Society}


Blunden, Jessica, NOAA/NESDIS National Centers for Environmental Information, Asheville, North Carolina

Boyer, T., NOAA/NESDIS National Centers for Environmental Information, Silver Spring, Maryland

Dunn, Robert, J. H., Met Office Hadley Centre, Exeter, United Kingdom

\section{Editorial and Production Team}

Allen, Jessicca, Graphics Support, Cooperative Institute for Satellite Earth System Studies, North Carolina State University, Asheville, North Carolina

Andersen, Andrea, Technical Editor, Innovative Consulting Management Services, LLC, NOAA/NESDIS National Centers for Environmental Information, Asheville, North Carolina

Hammer, Gregory, Content Team Lead, Communications and Outreach, NOAA/NESDIS National Centers for Environmental Information, Asheville, North Carolina

Love-Brotak, S. Elizabeth, Lead Graphics Production, NOAA/NESDIS National Centers for Environmental Information, Asheville, North Carolina
Misch, Deborah J., Graphics Support, Innovative Consulting Management Services, LLC, NOAA/NESDIS National Centers for Environmental Information, Asheville, North Carolina

Riddle, Deborah B., Graphics Support, NOAA/NESDIS National Centers for Environmental Information, Asheville, North Carolina

Veasey, Sara W., Visual Communications Team Lead, Communications and Outreach, NOAA/NESDIS National Centers for Environmental Information, Asheville, North Carolina 


\section{INTRODUCTION—T. Boyer, J. Blunden, and R. J. H. Dunn}

The singular most significant event for humankind in 2020 was the COVID-19 pandemic, with the disruption of human activity and everyday life. As the cover of this year's State of the Climate report intimates, while the world's human population struggled with the pandemic, signs of a changing climate did not abate. Even though emissions from fossil fuel use in 2020 dropped by $6-7 \%$ over the previous year due to decreased activity during the pandemic (section $2 \mathrm{~g} 1$ ), atmospheric concentration of the most important greenhouse gas, carbon dioxide $\left(\mathrm{CO}_{2}\right)$, still increased to the highest levels in the modern climate record (section 2g1). This is a stark reminder that factors leading to a changing climate are determined by time horizons far longer than a single year and have an inertia that will take a significant effort over a much longer period to halt, much less reverse. The effects of the drop in fossil fuel emissions are not discernable in atmospheric $\mathrm{CO}_{2}$ in 2020 over 2019 due to the relative magnitude of interannual variability in natural $\mathrm{CO}_{2}$ sources and sinks. Ocean carbon uptake (section 3j2), terrestrial photosynthetic activity (section 2h2) and, to a lesser extent, biomass burning (section 2h3) are some of the $\mathrm{CO}_{2}$ sinks and/or sources whose collective year-to-year variability is larger than, and indistinguishable from, the 2020 drop in fossil fuel emissions.

The pandemic did have a definite effect on the monitoring of Earth's climate system. For example, some permafrost sites went without regular in situ monitoring (section 2c1) due to travel difficulties arising from pandemic restrictions. Annual data from significant sections of the northern Atlantic meridional overturning circulation monitoring arrays were not gathered because of a lack of research cruises due to pandemic cancellations or delays (section 3h). Still, given that much of our quantification of climate variables comes from satellite information and climate reanalyses, the catalogue of essential climate variables presented in the State of the Climate in 2020 is as comprehensive as in prior years despite the difficulty of gathering in situ data related to the pandemic. The use of reanalyses, which incorporate (assimilate) observations into an underlying model of aspects of the climate system to numerically reproduce historic and recent climate conditions, helps to augment and extend the utility of satellite products and the sometimes scarce in situ observations. Ultimately bringing together all the observations, data and knowledge vital to the compilation of this report was accomplished through the continued and tireless efforts of more than 530 authors from 66 countries representing their colleagues and contributors from universities and agencies around the globe.

The State of the Climate in 2020 catalogues the two devastating hurricanes that hit Nicaragua and other Central American countries within two weeks of each other (section 4g2 and Sidebar 7.1), the hurricane with the strongest wind velocity to hit Louisiana in more than 150 years (Sidebar 4.1), and the strongest tropical cyclone to make landfall in the historic record (section 4g4), amongst many others tropical cyclones. The report also details the wet long-rain season in East Africa (sections $2 \mathrm{~d} 5,7 \mathrm{e} 4$ ) that raised lake levels (section $2 \mathrm{~d} 6$ ) and increased terrestrial water storage (section $4 \mathrm{~d} 9$ ) enough to affect global ocean mass storage (section 3f). The 2020 report further catalogues, for surface temperature, the third-highest temperature ever recorded anywhere in the world (pending certification) occurring in Death Valley, California $\left(54.4^{\circ} \mathrm{C}\right.$, sections $\left.2 \mathrm{~b} 3,7 \mathrm{~b} 2\right)$; Basra, Iraq, recording two successive days with maximum air temperature above $53^{\circ} \mathrm{C}$ (section $2 \mathrm{~b} 3$ ); and the highest temperature ever recorded in Antarctica (sections 2b3, 6a, Sidebar 6.1). Moreover, the State of the Climate in 2020 notes the Antarctic temperature record occurred during a persistent period of abnormally high air temperatures and was accompanied by the largest ever satellite recorded late-summer ice melt on the Antarctic Peninsula affecting more than 50\% of the area (section 6a, Sidebar 6.1). 
It is this last juxtaposition of climate statistics which demonstrates the utility of cataloging singular or short duration events in this annual compendium in order to put these events in the context of our current and changing climate. One event on its own is noteworthy, numerous events of a similar nature in one year interesting, but many of these being record breaking in the context of past observations concerning. A heat wave is defined using the statistical analysis of climatic surface air temperature, giving perspective on abnormally high and long duration surface air temperatures experienced in Antarctica and elsewhere in 2020. Likewise, the abnormally high and long duration sea surface temperatures in the North Pacific meet the statistical definition for a marine heatwave, one of unprecedented duration (section 2b3, Sidebar 3.1). Statistical analysis of cyclone activity and intensity in different ocean basins (section $4 \mathrm{~g}$ ) give some perspective on the likelihood of hurricanes/typhoons of the location and intensity experienced in 2020.

It is here that this annual report goes further than a simple compendium of events and their relation to long-term climate statistics. Many of the causes of singular weather events are also catalogued herein. Cyclone generation and intensity are related to a complex set of circumstances, many of them detailed in the State of the Climate reports. For example, upper ocean heat content is a factor in hurricane generation and intensity. Attempting to relate cyclone activity and upper ocean heat content in the quantity tropical cyclone heat potential (section 4h) is an important step in understanding and monitoring the climatic factors responsible for cyclogenesis and cyclone intensity. For global, annual conditions, (as opposed to singular or short duration events), comparing 2020 averages to the previous year and to the long-term average provides information on the importance both of long-term trends and interannual to decadal variability. An attempt to differentiate the annual influence of the long-term trend and seasonal to interannual factors on surface air temperature (section 2b1) is a step to clarifying the relative influence of climate trends and interannual factors on annual means of the variables that define our climate.

Few factors aside from long-term trends come up as often in the State of the Climate as the El Niño-Southern Oscillation (ENSO). The 2020 conditions with a transition to moderate La Niña mid-year is an important driver of many of the cataloged conditions in the State of the Climate. Due to ENSO not in phase with seasonal cycles, global annual means of some essential climate variables do not provide sufficient granularity to fully quantify the variable-more regional and intra-annual description is provided. For example, lake water level changes (section 2d6) are not unidirectional globally but are highly dependent on regional factors related both to ENSO and other drivers, such as the Indian Ocean dipole (IOD; section 4f). These differences are discussed and contextualized herein. As an added complexity, the nature of ENSO, IOD, and other phenomena are themselves changing as the climate system itself changes.

Finally, while there is already a large body of variables to monitor and understand climate, new variables and means of monitoring existing variables are continually developing, improving, and maturing. Rock glacier kinematics provides a new means of understanding the effects of interannual and longer-term variability in ground temperature (Sidebar 2.2). Data from a single cruise provide a snapshot of ocean acidification in the North Pacific (Sidebar 3.2), showing both effective regional monitoring and possibly a need for a more global quantification of this essential climate variable on the annual time scales. The State of the Climate continually catalogs new methods for monitoring essential climate variables and details where the global observation system can provide enhanced monitoring.

It is, of course, somewhat difficult to compare singular events and even annual means to climatic statistics when the climate itself is changing. There is a clear trend in most climate variables (Plate 1.1), but the magnitude of the trend is not always larger than the interannual variability. The difference in Plate 1.1 of this report from last year's report is nearly indistinguishable. However, the long-term, clear, consistent trends over the last 10, 50, or 150 years tracing the ongoing warming of our planet are striking. While it is important to have a yearly snapshot of the essential climate variables as a quick reference, the real value of the annual State of the Climate report is in placing singular events and annual means in the context of climate-both the long-term mean 
(climate) and the long-term trend (climate change). The State of the Climate report enables us to understand the year's events in terms of climate trends versus interannual factors. The report also showcases enhanced understanding and new means of measuring essential climate variables as well as illustrates further need for enhanced monitoring of these variables.

This year, the latest report from the Intergovernmental Panel on Climate Change (IPCC), The Physical Science Basis, will be released, representing a multi-year effort by scientists across the globe to quantify and qualify climate change. The IPCC report provides a definitive long view on climate change. The State of the Climate report augments the IPCC report with a higher frequency cataloging of climate information, contextualization of each individual year's singular events and collective state, and advances the current interim (between IPCC reports) state of the science for many essential climate variables.

The layout of the State of the Climate in 2020 is similar to previous years. Following this introduction (Chapter 1), Chapter 2 catalogs global climate, Chapter 3 the oceans, Chapter 4 the tropics, Chapters 5 and 6 the high latitudes (Arctic and Antarctic, respectively), and Chapter 7 other specific regions of the globe (North America, Central America/Caribbean, South America, Africa, Europe, and Oceania). Expanding the breadth of regional coverage this year are the additions of sections on Central Africa (section 7e3) and Central Asia (section 7g6). The Central Africa section includes information specific to Cameroon, Chad, Central Africa Republic, Democratic Republic of the Congo, Congo, Gabon, Equatorial Guinea, and São Tomé and Príncipe. Central Asia is defined as the region encompassing the countries of Afghanistan to the south; from east to west, Turkmenistan, Uzbekistan, Tajikistan, and Kyrgyzstan in the central part of the region; and Kazakhstan to the north. Finally, Chapter 8 is a listing of many (though not all) datasets used in the various sections of the State of the Climate in 2020 and a link to dataset access and further information. Datasets are listed by essential climate variables with a reference to chapter(s) in which the particular dataset was used. Most (though not all) datasets are readily downloadable by the reader who would like to reproduce the results found in the State of the Climate report or investigate further.

A large number of the datasets listed in Chapter 8 are from climate reanalyses and satellite products. However, the cover of Chapter 8 depicts the Atlantic Tradewinds Ocean-Atmosphere Interaction Campaign (ATOMIC; datasets detailed in Pincus et al., 2021; Quinn et al., 2021), an observational effort to measure all possible variables involved in air-sea interaction and cloud characteristics. It was conducted over an area near the island of Barbados from January to February 2020, mainly utilizing NOAA ocean and air platforms, a companion to the EUREC4A European field campaign in the same region. The importance of ATOMIC to the State of the Climate report is the expectation that research on the co-located observations will lead to better understanding of air-sea interaction and cloud characteristics, informing and improving future model iterations that underlay the reanalyses, which are used in the State of the Climate reports.

Time series of major climate indicators are again presented in this introductory chapter. Many of these indicators are essential climate variables, originally defined by the World Meteorological Organization's Global Climate Observing System (GCOS 2003) and updated again by GCOS (2010). As their name indicates, these variables are essential for a full understanding of the changing climate system. However, some of them are not available on the immediate timescales of this report, and others, particularly those dealing with the living world, are outside the scope of this report. 


\section{Essential Climate Variables-T. BOYER, J. BLUNDEN, AND R. J. H. DUNN}

The following variables are considered fully monitored in this report, in that there are sufficient spatial and temporal data, with peer-reviewed documentation to characterize them on a global scale:

- Surface atmosphere: air pressure, precipitation, temperature, water vapor, wind speed and direction

- Upper atmosphere: Earth radiation budget, temperature, water vapor, wind speed and direction

- Atmospheric composition: carbon dioxide, methane and other greenhouse gases, ozone

- Ocean physics: ocean surface heat flux, sea ice, sea level, surface salinity, sea surface temperature, subsurface salinity, subsurface temperature, surface currents, surface stress

- Ocean biogeochemistry: ocean color

- Ocean biogeosystems: plankton

- Land: albedo, river discharge, snow, fire, fraction of absorbed photosynthetically active radiation, groundwater, ice sheets and ice shelves, lakes, soil moisture

The following variables are considered partially monitored, in that there is systematic, rigorous measurement found in this report, but some coverage of the variable in time and space is lacking due to observing limitations or availability of data or authors:

- Atmospheric composition: aerosols properties, cloud properties, precursors of aerosol and ozone

- Ocean physics: subsurface currents

- Ocean biogeochemistry: inorganic carbon

- Land: above-ground biomass, anthropogenic greenhouse gas fluxes, glaciers, permafrost

- Surface atmosphere: surface radiation budget

The following variables are not yet covered in this report, or are outside the scope of it.

- Upper atmosphere: lightning

- Ocean physics: sea state

- Ocean biogeochemistry: nitrous oxide, nutrients, oxygen, transient tracers

- Ocean biogeosystems: marine habitat properties

- Land: anthropogenic water use, land cover, land surface temperature, latent and sensible heat fluxes, leaf area index, soil carbon 


\section{Acknowledgments}

The editors thank the BAMS editorial staff, in particular Bryan Hanssen, who provided technical guidance, oversaw publication of the report, and continues to help us shepherd the report into a digital publishing era; Hannah Kleppner, who provided peer review support; and Nicole Rietmann, who oversaw the hundreds of citations and references this year; and the NCEI Graphics team for facilitating the construction of the report and executing the countless number of technical edits needed. We thank our technical editor Andrea Andersen for her dedication and attention to detail. We also express our gratitude to Dr. Michael Alexander, who, for the first time, served as the AMS special editor for this report. Finally, we thank all of the authors and chapter editors who provide these valuable contributions each year, always with an aim to improve and expand their analyses for the readers.

Plate 1.1. Global (or representative) average time series for essential climate variables through 2020. Anomalies are shown relative to the base period in parentheses although base periods used in other sections of the report may differ. The numbers in the square brackets that follow in this caption indicate how many reanalysis (blue), satellite (red), and in situ (black) datasets are used to create each time series in that order. (a) NH polar stratospheric ozone (Mar) $[0,0,6] ;(b)$ SH polar stratospheric ozone (Oct) $[0,0,6]$; (c) apparent transmission (Mauna Loa) $[0,0,1]$; (d) surface temperature [2,0,4]; (e) lower tropospheric temperature [3,2,3]; (f) lower stratospheric temperature [3,3,0]; (g) extremes (warm days (solid) and cool days (dotted)) [0,0,1]; (h) Arctic sea ice extent (max [solid]) and min [dashed]; [0,0,1]); (i) Antarctic sea ice extent ( $\max$ [solid] and min [dashed]; [0,0,1]); (j) glacier cumulative mean specific balance $[0,0,1]$; (k) NH snow cover extent $[0,1,1]$; (I) lower stratospheric water vapor $[0,0,1] ;(\mathrm{m})$ cloudiness $[0,11,0] ;(\mathrm{n})$ total column water vapor - land $[3,1,1] ;(0)$ total column water vapor - ocean $[3,2,0]$; (p) upper tropospheric humidity $[1,2,0]$; (q) specific humidity - land $[3,0,1]$; (r) specific humidity - ocean $[3,0,1]$; (s) relative humidity - land $[2,0,1]$; (t) relative humidity - ocean $[2,0,1]$; (u) precipitation - land $[0,0,3] ;(v)$ precipitation - ocean $[0,0,1] ;(w)$ ocean heat content $(0-700 \mathrm{~m})[0,0,6] ;(x)$ sea level rise $[0,0,1] ;(y)$ tropospheric ozone [0,1,0]; (z) tropospheric wind speed at $850 \mathrm{hPa}$ for $20^{\circ}-40^{\circ} \mathrm{N}[4,0,0]$; (aa) land wind speed [0,0,1]; (ab) ocean wind speed [3,3,0]; (ac) biomass burning [0,2,0]; (ad) soil moisture [0,1,0]; (ae) terrestrial groundwater storage [0,1,0]; (af) fraction of absorbed photosynthetically active radiation (FAPAR) $[0,1,0]$; (ag) land surface albedo - visible (solid) and infrared (dashed) $[0,1,0]$. 

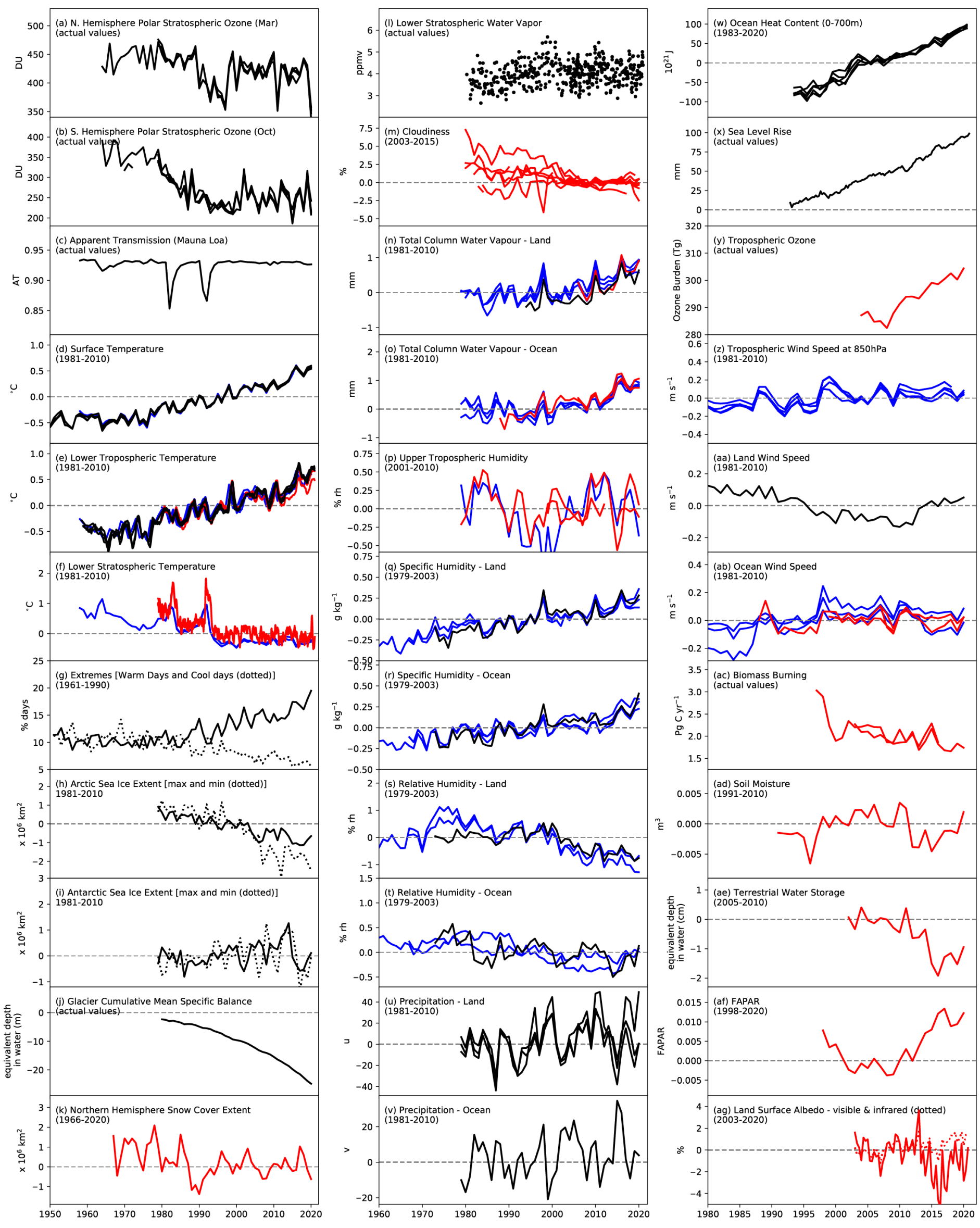


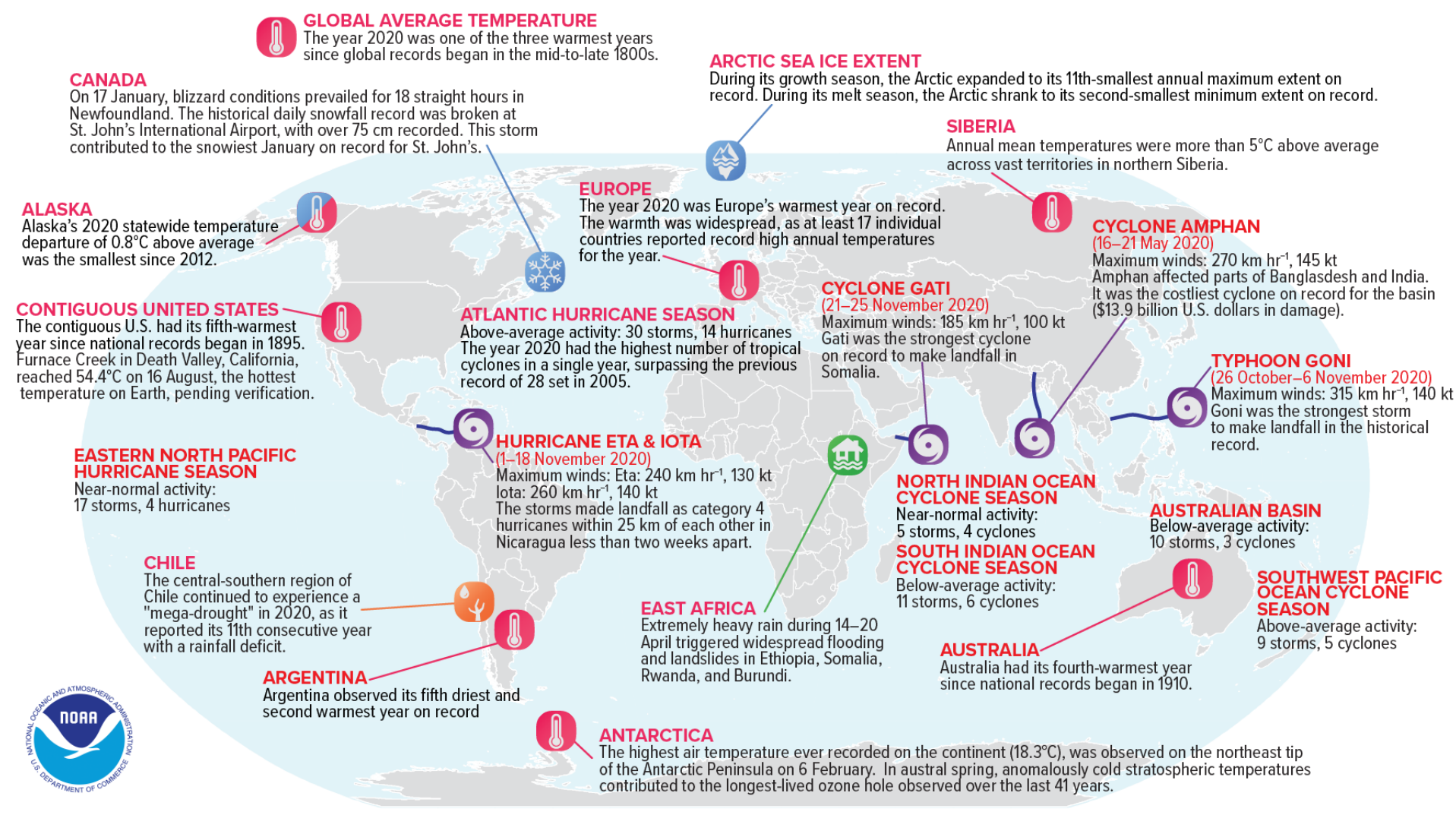

Fig. 1.1. Geographical distribution of selected notable climate anomalies and events in 2020. 